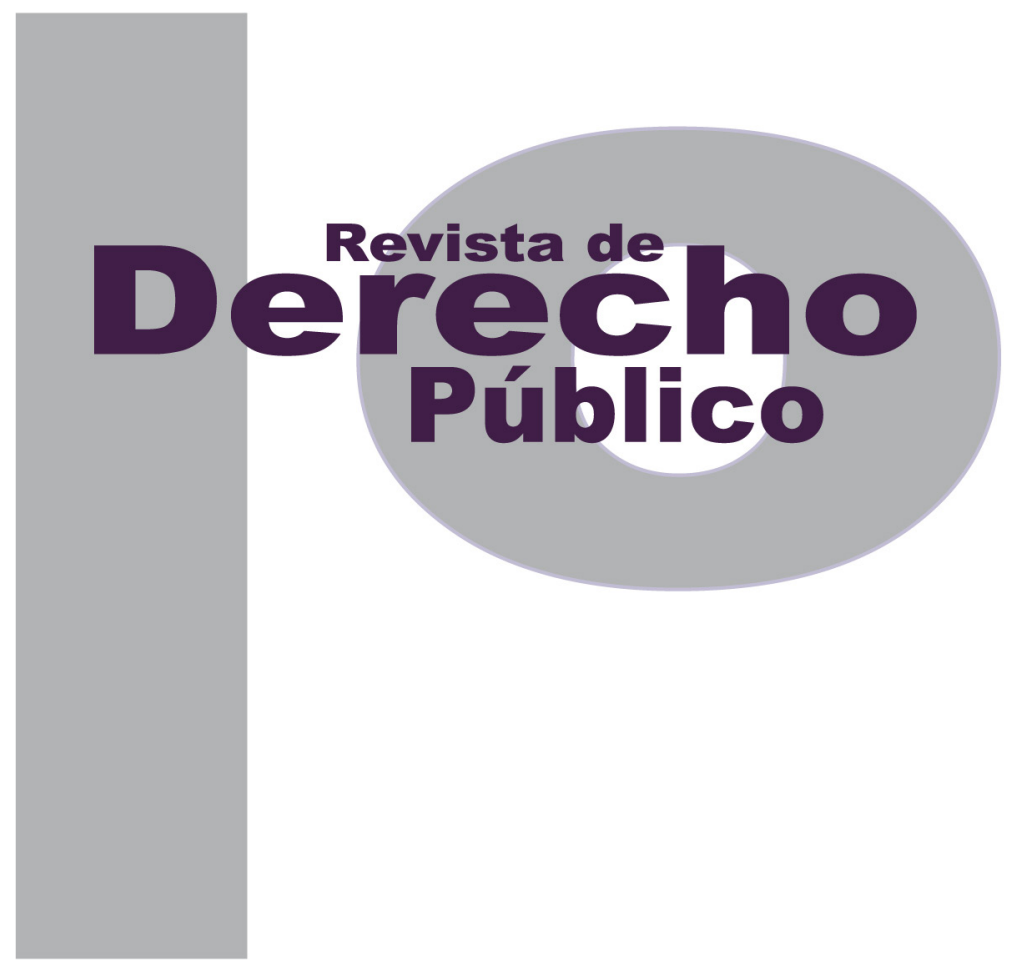

\title{
LA MONEDA ÚNICA SURAMERICANA. UN SUEÑO EN LA ENCRUCIJADA
}

\author{
JUAN FRANCISCO ORTEGA DÍAZ
}

Artículo de investigación científica y tecnológica

DOI: http://dx.doi.org/10.15425/redepub.36.2016.13

Universidad de los Andes

Facultad de Derecho

Rev. derecho publico No. 36

enero - junio de 2016. e-ISSN 1909-7778 


\section{La moneda única suramericana. Un sueño en la encrucijada}

\section{Resumen}

El presente trabajo analiza la viabilidad de la propuesta de creación de una moneda única para el continente latinoamericano, examinando los requisitos exigidos así como las ventajas e inconvenientes de la mencionada idea. Del mismo modo, se investiga la relación de esta nueva moneda con los procesos actuales de integración iberoamericana.

Palabras clave: moneda única, integración económica sudamericana, integración política.

\section{The unique South American currency: a dream in crossroads}

\section{Abstract}

This paper develops a viability analysis about the creation of a new common currency for Latin-American market; focus its attention in the necessaries requirements for its creation and the vantages and disadvantages of this new monetary instrument. Likewise, this works study the relation between this new common currency and the current Latin-American integration processes.

Keywords: Single currency, South American Economic Integration, Political Integration.

\section{A moeda única sul-americana. Um sonho na encruzilhada}

\section{Resumo}

O presente trabalho analisa a viabilidade da proposta de criação de uma moeda única para o continente latino-americano, examinando os requisitos exigidos assim como as vantagens e inconvenientes da mencionada ideia. Do mesmo modo, se investiga a relação desta nova moeda com os processos atuais de integração ibero-americana.

Palavras-chave: moeda única, integração econômica sul-americana, integração política. 


\title{
La moneda única suramericana. Un sueño en la encrucijada*
}

\author{
JUAN FRANCISCO ORTEGA DÍAZ**
}

\section{SUMARIO}

Introducción - I. REQUISITOS NECESARIOS PARA LA CREACIÓN DE UNA MONEDA ÚNICA - A. Requisitos económicos - 1. La necesidad de dos requisitos adicionales: el Banco Central Suramericano y la Política Fiscal Común - B. Requisitos políticos y jurídicos: el auténtico reto en el proyecto de construcción de la moneda única suramericana - II. BENEFICIOS E INCONVENIENTES DE LA MONEDA COMÚN - A. Reducción de costos de transacción - B. Aumento de la credibilidad - C. Costes por pérdida de independencia monetaria - III. CONCLUSIONES - Referencias.

* Cómo citar este artículo: Ortega Díaz, J. F. (Junio, 2016). La moneda única suramericana. Un sueño en la encrucijada. Revista de Derecho Público, (36). Universidad de los Andes (Colombia). http://dx.doi.org/10.15425/redepub.36.2016.13

** Doctor en Derecho por la Universidad de Salamanca (España). Profesor de planta, director de la Maestría de Propiedad Intelectual y director del Grupo de Estudios de Derecho de la Competencia y de la Propiedad Intelectual (GEDCOP), de la Universidad de los Andes. Correo: j.ortega43@uniandes.edu.co 
Introducción

A pesar del éxito que los modelos democráticos han tenido a nivel global tras la Segunda Guerra Mundial, en ese fenómeno que Huntington (1991) denominara olas democratizadoras, no parece realista establecer que la democracia no solo como sistema formal, sino como conjunto de principios y valores intrínsecos a una organización social determinada, sea un principio general en la sociedad internacional. Más bien parece una meta, un fin anhelado por muchas naciones que - 0 bien carecen de ella, o bien están dotadas de sistemas democráticos con una calidad muy baja- la persiguen con la convicción de que esta es el único camino por el que se transita hacia el desarrollo, el progreso y el respeto de la dignidad humana, esto es, la democracia como sinónimo de bienestar y de desarrollo económico. Basta examinar la realidad internacional para entender que dicha convicción está basada en la experiencia ajena. No en vano, los países más desarrollados - no solo desde una perspectiva económica sino también política y de garantía efectiva del cumplimiento de los derechos humanos- son democracias. Puede que sea imperfecta, pero como señaló Winston Churchill con su peculiar ironía política, "la democracia es la peor forma de gobierno, excepto por todas las otras formas que han sido probadas de vez en cuando" (Sebastián, 2002, p. 185).

En esta ansiada búsqueda de la democracia y el desarrollo económico por parte de las naciones que componen América Latina, una búsqueda presente ya desde los primeros años de la independencia - no en vano, las emergentes repúblicas latinoamericanas adoptaron unánimemente esta forma de gobierno- estas repúblicas, insisto, han visto en los procesos de unificación una forma de desarrollo y de consolidación de sus respectivos Estados democráticos. Estos procesos de integración, como es sabido, son múltiples y heterogéneos. Desde aquellos que han conseguido avances destacables, como Unasur, ${ }^{1}$ Mercosur ${ }^{2}$ o la CAN, ${ }^{3}$ hasta aquellos otros que, como el ALBA, ${ }^{4}$ superada su constitución como reacción al ALCA, ${ }^{5}$ parecen languidecer en la actualidad.

El proceso de integración latinoamericano -o los procesos emprendidos, para ser exactosson de carácter complejo y, en ocasiones, están manifiestamente destinados a una retórica política evidente. Solo algunos de ellos, vistos desde fuera, con cierta imparcialidad, tienen la posibilidad de consolidarse en el futuro y la oportunidad de llegar a convertirse en una auténtica realidad. Y, de entre todos ellos, sin lugar a dudas, Unasur es el ejemplo paradigmá-

\footnotetext{
1. Unión de Naciones Suramericanas.

2. Mercado Común del Sur.

3. Comunidad Andina de Naciones.

4. Alianza Bolivariana para los Pueblos de Nuestra América.

5. Área de Libre Comercio de las Américas.
} 
tico de proceso de integración, dotado de un relevante calado político (Díaz Barrado, 2005). No es de extrañar, por tanto, que sea precisamente en el marco de Unasur desde donde los gobiernos de dos países diferenciados, Brasil y Ecuador, hayan propuesto dar un paso más en este proceso de integración lanzando la idea de una moneda única suramericana -a imagen y semejanza del euro- para todos los países miembros de Unasur.

La propuesta se fundamenta, al igual que ocurriera en el ámbito de la Unión Europea, en dos vertientes diferenciadas: la política y la económica. La política, así como fuera en el Viejo Continente el sueño napoleónico de una gran Europa, es en América Latina el sueño de Simón Bolívar: el de aglutinar a todos los pueblos de las Américas. Y, en cierta forma, este sueño es un elemento esencial del imaginario colectivo de todos los países latinoamericanos que, a pesar de las dificultades, tienden a dicha integración. En algunos países, como en el caso colombiano, este elemento -que bien podríamos llamar identitario de muchos países latinoamericanos- se encuentra constitucionalizado en el propio preámbulo de la Constitución Nacional, al señalar: "Y comprometido a impulsar la integración de la comunidad latinoamericana, decreta, sanciona y promulga la siguiente Constitución Política de Colombia." De la misma manera, en su art. 9.2 insiste en el mismo sentido: "De igual manera, la política exterior de Colombia se orientará hacia la integración latinoamericana y del Caribe." Si tenemos presente que la Constitución colombiana vigente es del año 1991, debemos descartar que este elemento sea un mero rezago del pasado sino que, muy al contrario, es un elemento vivo que persiste en la esencia política del país. La segunda vertiente, la económica, es, sin duda alguna, mucho más compleja. A mi juicio, para entenderla, es preciso tener presente dos aspectos diferenciados. En primer lugar, la importancia que, como bloque, una unión de estas características tendría. A título ejemplificativo, los países que conforman Unasur generan un PIB de 3.361.672 M.€ con una población de 412.296 .000 habitantes, a fecha de 2015 (Unasur, 2014), y constituye -con la importancia estratégica que ello conlleva- ser el primer productor mundial de alimentos. En definitiva, si Unasur tuviera una presencia de bloque, en el ámbito económico y a nivel internacional, nos encontraríamos ante la quinta potencia económica del mundo. En segundo lugar, las potencias económicas suramericanas, Brasil entre ellas y como ejemplo más ilustrativo, pertenecen a Mercosur, un proyecto de integración que, con una Unasur desarrollada política y económicamente -como un auténtico proceso de integración con cesión de soberanía de los Estados y un mercado común-sería, por decirlo de algún modo, felizmente fagocitado.

Ante esta realidad, ¿por qué seguir dependiendo en el ámbito de la política monetaria del llamado "patrón dólar" y, en menor medida, del "patrón euro"?, ¿por qué no acuñar y emitir una moneda propia que, por un lado, favorezca el proceso de integración económico, impulsando la futura integración política, y que, por otro, otorgue mayores posibilidades en política cambiaria a la región?, ¿sería esto posible, 
como proclaman los gobiernos de Brasil y de Ecuador, o, por el contrario, sería una quimera, una aspiración imposible?, ¿cuáles son los beneficios, pero también cuáles los costes que la puesta en práctica de esta iniciativa conllevaría? Al examen de estas cuestiones dedicaré las siguientes páginas.

\section{REQUISITOS NECESARIOS PARA LA CREACIÓN DE UNA MONEDA ÚNICA}

Una de las cuestiones que generan una opinión cercana a la unanimidad, y que parece configurarse como un requisito imprescindible para la implantación exitosa de una moneda única en un mercado conformado por Estados diferentes, es la necesidad de una cierta homogeneización de las economías en las que la nueva moneda encontrará su hábitat natural. Y ello es así porque, no olvidemos, una moneda no deja de ser un título representativo, esto es, un documento que representa un valor determinado y que está respaldado por uno o varios Estados. Este respaldo no es algo abstracto, sino que se materializa en la capacidad real que dicho Estado -o grupo de Estados- tiene para respaldar con riqueza real el valor representativo contenido en el título. Esta riqueza tampoco es abstracta, pues se garantiza a través de las llamadas "reservas estatales monetarias", tradicionalmente una cantidad determinada de oro -patrón oro-(Yeager, 1984, pp. 553-556) que asegura el valor y la fiabilidad de la moneda. No obstante, y tras la Conferencia de Bretton Woods en 1944, en la cual se crearon el Banco Mundial y el Fondo Monetario Internacional, se adoptó el llamado patrón dólar. Mediante este, el dólar sustituyó al oro como referencia de valor y respaldo de las monedas mundiales, estableciendo, de una parte, un valor fijo al dólar respecto al oro y, de otra, a las restantes monedas un valor fijo en dólares, siendo a su vez todas ellas convertibles entre sí. Como es comprensible, la medida no fue inocente pues al implantar en el comercio internacional este nuevo estándar, la importancia del dólar y de los EE. UU. en la economía internacional se volvía aún más preponderante, si cabe.

Entender la realidad de la moneda como título representativo es un elemento imprescindible para comprender cómo puede funcionar una moneda única y los peligros que, un uso irresponsable de ella, puede generar. Una de las tentaciones propias de los gobernantes, especialmente en algunos países de América Latina -el caso argentino, bajo el gobierno de Carlos Menem es, sin duda el ejemplo por excelenciaes entender que, si hace falta dinero, el Estado tiene una solución sencilla y rápida: la emisión de más moneda. En último término, es el Estado quien la produce. Este es un error de graves consecuencias y un ejemplo de confusión entre riqueza real y título representativo (dinero). Emitir más dinero, sin una riqueza real que lo sostenga, genera la desconfianza de quienes lo poseen. El resultado que se produce de manera inmediata es la inflación, esto es, que, ante la desconfianza de que el Estado pueda pagar el valor representado por el dinero, los que poseen riqueza real en el mercado -prestadores de bienes y servicios- exigen más dinero por las mismas prestaciones con el fin de poder 
cubrir posibles pérdidas por impago o por devaluación de la moneda. Nos hallamos así ante la tan temida inflación: el aumento generalizado y sostenido de los precios de los bienes y servicios existentes en el mercado durante un período de tiempo determinado. En Argentina, a finales de los años ochenta y tras la práctica de esta política económica, la inflación llegó a unas tasas tan altas que los supermercados etiquetaban, cada vez con precios más altos y en un solo día, hasta tres veces sus productos.

La inflación, se ha repetido hasta la saciedad en la literatura económica, es el cáncer de una economía eficiente. Por ello, si una moneda quiere operar en diferentes Estados, y, por tanto, en diferentes economías, es imprescindible que los niveles de inflación sean más o menos similares (Anchuelo, 1998, p. 54). Todo ello, sea defendido desde estas páginas, sin convertir, al estilo de los neoliberales económicos, la inflación en el único elemento a tener en cuenta a la hora de establecer políticas monetarias.

Por ello, y siendo la inflación posiblemente el requisito más importante como consecuencia de las interferencias que tasas heterogéneas de esta pueden causar en los diversos Estados que comparten una misma moneda, no es este el único requisito a tomar en cuenta. Detengámonos a examinar esta cuestión algo más detalladamente.

\section{A. Requisitos económicos}

La pregunta relativa a qué requisitos se deben cumplir por las economías que integran una moneda única no es nueva en la escena internacional. Durante un largo periodo de tiempo, los impulsores del euro debatieron y se cuestionaron esta incógnita durante el proceso de diseño e implantación de este (Sáez Fernández, 1994; Fernández Navarrete, 1999) en la actual Unión Europea. Recordemos que esta es fruto de un proceso de integración que hoy suma veintiocho países que no solo comparten moneda, sino que conforman un único mercado; algo que, cabe destacarlo, en el ámbito latinoamericano de Unasur, no se ha propuesto tan abiertamente. En este sentido, y siguiendo el ejemplo marcado por el euro, cuatro parecen ser los criterios que, a priori, de manera necesaria, deben cumplir las diferentes economías para la operatividad de una moneda única:

a) Estabilidad de precios: este es el llamado requisito inflacionario. Tanto la consecución de una alta estabilidad de precios como un mantenimiento sostenido de la inflación, son elementos cruciales. En este sentido, de manera clara lo señalaba el art. 121.1 del Tratado Constitutivo de la Comunidad Europea (TCE), el cual recogía estos requisitos -en el derecho comunitario europeo recibieron el nombre de criterios de convergencia-:

El logro de un alto grado de estabilidad de precios, que deberá quedar de manifiesto a través de una tasa de inflación que esté próxima a la de, como máximo, los tres Estados miembros más eficaces en cuanto a la estabilidad de precios.

Sin embargo, la expresión "que esté próxima a" no resultaba del todo satisfactoria, 
por no decir concreta, y muy pronto se aclaró al establecer que la tasa de inflación referida en el precepto señalado no debía rebasar en más de 1,5 puntos porcentuales la de los tres Estados miembros con mejor comportamiento en materia de estabilidad de precios, observada durante un período de un año antes del examen.

b) Equilibrio presupuestario público: los Estados en los que opera una moneda única deben tener unas similitudes mínimas que otorguen fiabilidad a la moneda. El valor de una moneda común se calcula, con toda la simplificación que esta afirmación implica, aunando la riqueza - pero también las deudas- de todos los Estados que la comparten. Por ello, el objetivo de la reducción del déficit público se plantea como el segundo objetivo más importante detrás de la reducción de la inflación. A pesar de ello, este es un tema controvertido. Para los ultraliberales económicos, o fundamentalistas del mercado - por utilizar el término de Hobsbawm (2011) -, la inexistencia de deuda pública es un ideal propio de una economía perfecta (De la Dehesa, 1998, p. 81).

Por el contrario, muchos otros, entre los que me incluyo, creen que la deuda es un instrumento en la política económica como cualquier otro y que no debe sustraerse a la acción de los Estados. Una deuda desmesurada conlleva incapacidad de financiación del Estado, una pérdida de valor de la moneda a través del tipo de cambio y, en ocasiones, es causa del aumento de la inflación.
No obstante, la no obtención de financiación por parte del Estado, a través de su endeudamiento, conlleva generalmente la incapacidad de realizar inversión pública que, en su caso, genera empleo directo, consumo y dinamiza la economía. Un justo equilibrio entre ambos parece ser lo ideal. En América Latina este tipo de inversión es crucial para el desarrollo de programas estructurales en infraestructura, educación y salud, sin los cuales el impulso al desarrollo es casi imposible. El Ilamado milagro ecuatoriano es un claro ejemplo de ello. Durante casi una década el Gobierno ecuatoriano renegoció la deuda pública que tenía y reinvirtió el diferencial en este tipo de infraestructuras, llegando a reducir en poco más de una década su deuda externa a la vez que acometía inversión pública para el desarrollo.

\begin{tabular}{|l|c|c|c|}
\hline \multicolumn{4}{|c|}{ Ecuador: Evolución de la Deuda } \\
\hline & Millones $€$ & $\%$ PIB & $€$ Per Capita \\
2014 & 23.677 & $31,30 \%$ & 1.477 \\
2013 & 18.485 & $25,99 \%$ & 1.172 \\
2012 & 14.779 & $21,68 \%$ & 952 \\
2011 & 11.071 & $19,43 \%$ & 725 \\
2010 & 10.314 & $19,68 \%$ & 687 \\
2009 & 7.954 & $17,72 \%$ & 540 \\
2008 & 9.332 & $22,24 \%$ & 645 \\
\hline 2007 & 10.122 & $27,20 \%$ & 712 \\
2006 & 10.745 & $28,83 \%$ & 769 \\
\hline 2005 & 11.669 & $35,02 \%$ & 850 \\
2004 & 11.700 & $39,76 \%$ & 863 \\
\hline 2003 & 12.869 & $44,87 \%$ & 966 \\
\hline 2002 & 15.876 & $52,52 \%$ & 1.203 \\
\hline 2001 & 17.021 & $62,30 \%$ & 1.328 \\
\hline
\end{tabular}

Fuente: http://www.datosmacro.com/deuda/ecuador 


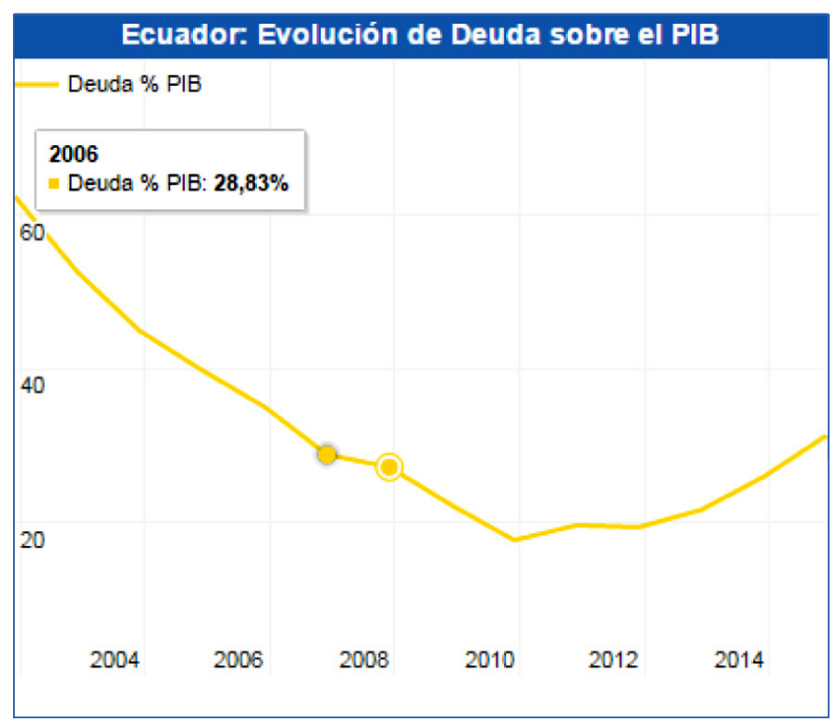

Fuente: http://www.datosmacro.com/deuda/ecuador

El caso europeo, el TCE, ex art. 121.1, recogió este precepto con claridad al señalar: “las finanzas públicas deberán encontrarse en una situación sostenible, lo que quedará demostrado en caso de haberse conseguido una situación del presupuesto sin un déficit público excesivo". Con todo, y al igual que ocurriera con el criterio inflacionista, las instituciones comunitarias establecieron medidas para determinar el cumplimiento de este criterio de convergencia, con base en dos aspectos económicos bien diferenciados:

- El déficit público anual: la proporción del déficit público anual en el producto interior bruto (PIB) no debe rebasar el 3\% al final del ejercicio presupuestario anterior. Si ello no es así, dicha proporción debe haber disminuido de forma sustancial y constante, y haber alcanzado un nivel próximo al 3\% (consideración de la tendencia según el artículo 104.2 TCE), o haber sobrepasado solo excepcional y tem- poralmente el valor de referencia del 3\% y mantenerse cercano a dicho valor.

- La deuda pública: la proporción entre la deuda pública bruta y el PIB no debe rebasar el $60 \%$ al final del ejercicio presupuestario anterior. Si ello no es así, dicha proporción debe haber disminuido suficientemente y acercarse a un ritmo satisfactorio al 60\% (consideración de la tendencia, según el art. 104.2 TCE).

c) Tipo de cambio: el establecimiento de una moneda común implica un reajuste del valor de cada una de las monedas nacionales, para confluir en la nueva moneda. Este cálculo debe realizarse teniendo en cuenta el valor representativo que cada Estado otorga a su moneda. Por ello, si los Estados, poco antes de la adopción de la moneda común devalúan el valor de esta, sus ciudadanos obtienen una ventaja injusta -incremento patrimonial- frente a la nueva moneda. Así, una devaluación antes de la adopción de la moneda común serviría para que los ciudadanos de un determinado Estado obtengan un tipo de cambio más favorable.

En el caso europeo, especialmente con países como Italia y España que tenían una larga tradición en la práctica de la devaluación de sus monedas nacionales, este temor estuvo muy presente durante el diseño del euro. Por ello, no es extraño que uno de los criterios de convergencia sea precisamente este, recogiéndolo de manera expresa el propio art. 102 TCE al exigir 
el respeto, durante dos años como mínimo, sin que se haya producido devaluación frente a la moneda de ningún otro Estado miembro, de los márgenes normales de fluctuación que establece el mecanismo de tipos de cambio del sistema monetario europeo.

Junto a todo ello, en materia de tipo de cambio, existían otros temores fundados. Uno de ellos se refería al hecho que un Estado podía no devaluar su moneda pero sí alterar el valor de esta. Para evitarlo, el TCE exigió que los Estados que quisieran entrar en el euro tuvieran que haber participado en el mecanismo de tipos de cambio del sistema monetario europeo sin interrupción durante los dos años anteriores al examen de su situación, sin haber sufrido tensiones graves. Por supuesto, y como es obvio, se prohibió que cualquier Estado devaluara sus monedas nacionales por las razones ya expuestas.

d) Tipo de interés a largo plazo: este es, posiblemente, el criterio de convergencia más complejo de entender. El requisito es el siguiente: el tipo de interés nominal a largo plazo no debe ser superior a un $2 \%$ con respecto a la media de los tres Estados con menores tasas de inflación -los mismos Estados que servían de referencia para el criterio inflacionista-durante el año precedente al examen.

Si en un mercado único como es el europeo, los diferentes Estados permiten intereses crediticios muy dispares, el crédito se concentraría en algunos de los países que ofrezcan los intereses más bajos a largo plazo. Para evitar esta posible distorsión se impuso este criterio que fue fácilmente cumplido por los países miembros.

1. La necesidad de dos requisitos adicionales: el Banco Central Suramericano y la Política Fiscal Común

En lo que respecta a la moneda única suramericana, los requisitos señalados, si bien son necesarios, no son suficientes. A mi juicio, su implantación debe ir acompañada de dos medidas bien definidas:

a) Un banco central suramericano: en oposición a lo que ocurre en el ámbito de la Unión Europea, Unasur no posee una institución que cumpla con las funciones de un banco central. Y esta función, para el correcto mantenimiento de una moneda única, es esencial. Recordemos que una institución de este tipo es necesaria, porque su principal función es el sostenimiento del valor de la moneda única y el mantenimiento de los precios así como, por supuesto, ser el responsable de la emisión y destrucción de dinero (Gutiérrez del Castillo, 1997). Igualmente, una función crucial de un banco central sería el mantenimiento de la estabilidad y fiabilidad del sistema financiero de todos los países que integrarían esta moneda única sudamericana.

Al contrario de lo que, desde principios de los ochenta, la doctrina económica liberal o 
ultraliberal nos ha hecho creer, la economía no se circunscribe, únicamente, a una mera cuestión técnica e indiscutible. La economía es ideología y, en pocas situaciones como en la del diseño de un banco central, esta dicotomía se puede verificar con más claridad. Uno de los elementos que caracteriza a los bancos centrales de la mayoría de los países occidentales es su carácter independiente, esto es, la toma de decisiones en materia económica -principalmente a través de las relacionadas con la modificación de las tasas de interés de la moneda que controla- está desligada del poder político, pues, se dice, esta independencia evita las tentaciones inflacionistas, o populistas, del Poder Ejecutivo, lo que favorece una mejora de la inflación y de la estabilidad de los precios (Blinder, 1999, pp. 54-55). Y esto puede ser cierto, o no. En este sentido, cabe precisar que la ideología neoliberal surgida a partir de finales de los años setenta impuso una especie de nuevo sentido común económico (Nun, 2015, pp. 187-192). Así, los teóricos neoliberales defendieron con ahínco, casi como una verdad revelada, determinadas posiciones económicas que se convirtieron en auténticos dogmas de la fe neoliberal. Medidas como la pérdida de derechos de los trabajadores y la precariedad laboral -los neoliberales hablan de reforma laboral y contención salarial- favorecerían la creación de empleo; la reducción de impuestos a los más pudientes aumentaría la inversión económica y la generación de puestos de trabajo; la apertura de las fronteras aumentaría las exportaciones de los países, independientemente de con respecto a quién. Todas son creencias que apenas se han puesto en cuestión desde aquella época. Sin embargo, a día de hoy, no hay una sola prueba de que estas medidas generen los efectos que prometen, más bien, todo lo contrario (Krugman, 2009; Stiglitz, 2012, pp. 19-21). Asimismo, la independencia de los bancos centrales es otro de estos dogmas que, a mi juicio, si bien no debe ser descartado de plano, sí debe ser sometido a determinados criterios moduladores, tal como explicaré a continuación.

La pregunta que surge a continuación es sencilla, ¿si quienes fijan estas decisiones son independientes, alejados del poder político, a los que nadie eligió directamente, podemos estar seguros de que aplicarán políticas conforme a los intereses generales o, únicamente, conforme a los intereses de determinados sectores del mercado? Una de las cuestiones más delicadas que plantea el aspecto de la independencia de los bancos centrales es su ausencia de legitimidad democrática. De manera muy clara lo ha expresado parte de la doctrina constitucionalista española al señalar:

El problema estriba en primer lugar, en que un banco central independiente no incorpora los criterios de legitimidad democrática que son necesarios en todo Estado constitucional. En efecto, en un Estado constitucional la vigencia del principio democrático impide la existencia de administraciones propiamente independientes, cualquiera que sea su fina- 
lidad. Por lo tanto, la existencia de bancos centrales independientes, en el pleno sentido del calificativo, altera el sistema de origen y control democráticos y no es propio de una democracia constitucional. (Martínez Dalmau, 2007).

En este trabajo no puedo hacer otra cosa que plantear el interrogante de manera somera e indicar que, a la vista está, no parece que las decisiones de muchos bancos centrales -especialmente el Banco Central Europeo-se tomen pensando en el beneficio de los ciudadanos sino, más bien, en el rendimiento inmediato de los movimientos de capital que operan en los mercados financieros, es decir, las instituciones públicas al servicio de intereses privados. En cualquier caso, no debemos ocultar que esta discusión acerca de la independencia de los bancos centrales se inserta en otra, aún más amplia, relativa a las tesis neokeynesianas y las monetaristas, que se diferencian en el impacto de la política monetaria en la economía real (David, 1978, pp. 121-142). Por ello, máxime en un entorno como el latinoamericano, parecería conveniente pensar en algún mecanismo de control a este carácter independiente, que no deje únicamente a los gobiernos, o al menos no los deje de manera absoluta, relegados en el ámbito de la política monetaria. La solución, si el proyecto de moneda única suramericana avanza, deberá ser planteada y definida en los próximos años, intentando solventar los problemas de legitimidad democrática y de ausencia de control democrático que actualmente parecen imperar en las instituciones occidentales de esta clase (Martínez Dalmau, 2005).

b) La política fiscal común: una de las enseñanzas que dejó tras de sí la experiencia del euro, en la Unión Europea, fueron las interferencias que se producían en la moneda común, y muy especialmente en el poder adquisitivo de los ciudadanos de los distintos países que la integran, a raíz de políticas fiscales, en ocasiones claramente contrapuestas, por parte de los gobiernos de los diferentes Estados. Este es un error que, en el proyecto de moneda única suramericana, no puede volver a cometerse. Voces de reconocido prestigio en el ámbito de la teoría económica, entre ellas la de De Grauwe (1994), han señalado:

Una unión monetaria (...) debe ir acompañada de algún grado de centralización de los presupuestos nacionales. En concreto, el sistema de protección frente al desempleo y una parte importante de los impuestos sobre la renta deberían estar centralizados, de forma que dicha centralización permitiría realizar transferencias automáticas hacia regiones y países afectados por shocks negativos. (Pp. 190-191).

Al no haber sido así, y lo vemos diáfanamente en la zona euro, se han producido serias divergencias sobre los distintos países donde opera la misma moneda. Por ello es imprescindible una coordinación -o integración común- de las políticas finan- 
cieras -en especial, la política fiscal-y de las monetarias. Cabe recalcar que esta necesidad fue advertida en el lejano ya 1999 por algunos economistas italianos que preconizaban los problemas en la zona euro que finalmente se produjeron (Bini Smaghi y Casini, 2000). En América Latina, tras la crisis del petróleo de los años setenta, la coordinación entre estas dos políticas se consideró, por parte de la doctrina científica latinoamericana, una auténtica necesidad, puesto que la política macroeconómica tradicional fue incapaz de corregir los graves problemas económicos de la región (Garay Salamanca, 1994). Así, finalizados los años setenta Dieterich (1979, p. 23) señalaba:

En vista de la experiencia de los últimos años y de la evolución de los estudios teóricos, ya no es posible considerar apropiada la aplicación de políticas fiscal y monetaria por separado o supeditada la una a la otra. Al hacerlo se correría el riesgo de agravar los problemas de coyuntura y posponer indebidamente la respuesta a los de estructura. Resulta indudable que la solución a este depende del logro de un delicado equilibrio entre ambas políticas, fundado en la operación articulada de todos los instrumentos de política monetaria y en la precisa identificación de los objetivos en el tiempo y en el espacio, dentro de un adecuado clima político.

Por ello una política fiscal común, integrada o cuando menos coordinada, parecería configurarse como una exigencia ineludible. Basta examinar la realidad política latinoa- mericana para entender que una única política fiscal coordinada, menos aún un acto de integración real, entre los diferentes países aspirantes a emplear una única moneda, es a nivel práctico un deseo casi imposible. Así, es muy difícil imaginar la coordinación de una política fiscal entre la Argentina del presidente Macri, un neoliberal a ultranza, y la dirigida por el presidente Correa, de Ecuador, quien ha implementado una política fiscal de corte socialdemócrata.

\section{B. Requisitos políticos y jurídicos: el auténtico reto en el proyecto de construcción de la moneda única suramericana}

Junto a todos los requisitos de carácter estrictamente económico, la puesta en marcha de un proyecto como la moneda única suramericana exige, además, una fuerte apuesta de carácter político y jurídico. Y ambos elementos están intrínsecamente unidos.

El despegue de la nueva moneda debe ser consecuencia, ineludiblemente, de un fuerte avance en el proceso de integración latinoamericana en el marco de Unasur; un proceso de integración que, a día de hoy, no avanza a la velocidad que un proceso de estas características exige. ¿A qué se debe eso? La respuesta es relativamente sencilla en lo teórico, y muy compleja a la luz de la realidad y de la concepción política latinoamericana. La única manera de consolidar un proyecto de integración, para la adopción de medidas que permitan tener 
una legislación armonizada y políticas comunes, es la cesión de soberanía por parte de los Estados a Unasur. En el proyecto que nos ocupa, esta cesión de soberanía es prácticamente imprescindible para la puesta en marcha, con garantías, de la moneda única. Crear un banco central, establecer políticas fiscales uniformes, regular o fijar sanciones para los Estados que no cumplan con las condiciones de acceso para la moneda única -los criterios de convergencia, por usar la terminología europea- serían sumamente complejos, cuando no imposibles, en el supuesto de no efectuarse esta cesión.

Con todo, la mera cesión de soberanía no es suficiente. Esta debe ir acompañada de un compromiso por parte de los países más prósperos, de un compromiso solidario de ayuda hacia aquellos otros que, cumpliendo o estando próximos a cumplir las condiciones que permiten el acceso a la moneda única, necesitan apoyo financiero para alcanzar las mencionadas condiciones, y en la medida de lo posible, para homogeneizar su economía con el resto de los países miembros. Sin lugar a dudas, este proceso es más sencillo en el ámbito de la teoría que en el de la práctica. A la hora de poner en marcha un acuerdo de este tipo, los países con economías más potentes deben crear fondos específicos cuya finalidad sea transferir a países con economías más endebles, recursos solidarios para destinarlos a inversiones que irían no solo a mejorar las infraestructuras que faciliten el desarrollo del comercio sino también para avalar el apoyo monetario para políticas tipo cambiarias que favorezcan las condiciones de acceso a la moneda única.
La ejecución de todo ello requeriría, finalmente, la creación de un armazón jurídico bien consolidado que debería girar alrededor de los dos sujetos internacionales directamente afectados: Unasur y Mercosur. Los países latinoamericanos -que con total seguridad serían miembros de Unasur pues el proyecto de moneda única se ha planteado desde su seno- se verían obligados a iniciar una adaptación institucional de Unasur con el fin de garantizar que esta pudiera liderar un proyecto de este tipo. Para ello, a mi juicio, en primer lugar se debería realizar un tratado constitutivo en el que se acuerde la transformación de Unasur con las nuevas competencias cedidas por los Estados. En segundo lugar, acordar en un nuevo tratado, por disciplina sistemática jurídica, las condiciones de acceso, control y puesta en funcionamiento de la nueva moneda: requisitos a cumplir por los Estados que compartirían la moneda, creación y regulación de un banco central, procesos de transformación de monedas nacionales a la nueva moneda común, procedimientos sancionatorios ante incumplimientos de los países miembros, etc.

Ahora bien, la aprobación de estos tratados, jurídicamente, no sería sencilla. Y ello es así porque, más allá del logro del acuerdo entre los Estados miembros, en caso de conseguirse, su aprobación con la cesión de soberanía implicaría la reforma constitucional de prácticamente la totalidad de las Cartas Magnas de Ios Estados; unos procesos de reforma que, si bien no son imposibles, sí son realmente complejos. 
Y, en este planteamiento teórico, los problemas más evidentes no tardarían en aparecer. El primero de ellos es, lo que a mi juicio, constituye una contradictio in terminis. No parece razonable tener una moneda común si, en realidad, los países que la comparten no poseen un mercado único. $Y$ este es el primer gran escollo. Ante esta observación, podría atemperarse el hecho alegando que Mercosur es una realidad palpable, un bloque económico de indudable importancia y que, dicho esto con todas las restricciones, podría definirse como un protomercado único con muchas imperfecciones. Aun aceptando esta realidad, lo cierto es que, miembros plenos, son solo cinco países de la totalidad de los que componen Unasur, si bien el número se eleva a once si contamos los miembros asociados. En cualquier caso, Mercosur requeriría un proceso de integración mayor y su constitución como un auténtico mercado único que acogiera de facto el establecimiento real de una posible moneda única.

Existiendo un mercado único al que se adhirieran los países que quieren formar parte de la moneda única (Mercosur), su puesta en marcha sería más fácil. Aun así, esta realidad Ilevaría, más pronto que tarde, a la fagocitación de Mercorsur por parte de Unasur. Si todos los miembros de Mercosur, o, al menos, los miembros más importantes, formaran parte de la moneda única, lo lógico es que las decisiones se adopten en una misma organización y no en dos diferentes. Y esta, por proyecto político de integración regional de carácter integral y no únicamente económico, solo puede ser Unasur.

\section{BENEFICIOS E INCONVENIENTES DE LA MONEDA COMÚN}

Llegados a este punto, y tras hacer un análisis conciso de los requisitos y de los retos a los que se enfrentaría el proyecto de moneda única suramericana, cabe analizar si, en realidad, un esfuerzo de estas características tendría la recompensa esperada. Dicho en otros términos, se trata de conocer qué ventajas e inconvenientes, si los hubiere, aportaría la creación de esta nueva moneda común.

\section{A. Reducción de los costos de transacción}

Una de las claves que parecen poco discutibles es la relativa a la reducción de los riesgos cambiarios en las transacciones comerciales y en las de inversión, entre los países miembros de una moneda común, pues se eliminan los costos de transacción que surgen de la necesidad de operar con múltiples monedas. Adicionalmente, la moneda única provocaría tipos de cambio fijos, eliminando la volatilidad cambiaria entre los socios comerciales.

Estas dos ventajas, a priori, reducirían costes, aumentarían los niveles de información de los operadores económicos participantes en relación con el valor de la moneda empleada e incrementarían la competencia entre las empresas de los diferentes países de la zona donde la moneda común operara. En un ámbito como el latinoamericano, es previsible que los países menos desarrollados se vean beneficiados, pues al ser común su moneda, el valor se 
calcula sobre la riqueza de todos los Estados miembros y no, únicamente, sobre la nacional propia, extremo que permite una solvencia adicional de estas empresas, y una mayor protección frente al riesgo, en las transacciones con otros países. En este sentido, autores destacados han señalado:

Que la formación de una unión monetaria en sí incrementará sustancialmente la integración comercial, y que cuanto mayores sean los flujos de comercio e inversión entre los países, mayores serán las ventajas de una reducción de los costos de transacción. (Nitsch, 2002; Rose, 1999).

\section{B. Aumento de la credibilidad}

Una moneda única genera, en los mercados, la existencia de una limitación creíble por parte de los Estados a la hora de emitir dinero, restringiendo la posibilidad de políticas monetarias cortoplacistas que, a largo plazo, pudieran producir desastres inflacionistas. De ahí que, por decirlo de algún modo, una moneda única sea una garantía de tasas de inflación bajas y estables (Persson, 2001; Tenreyro, 2013), lo que, sin lugar a dudas, es bueno para la estabilidad económica y para un crecimiento sostenido que favorezca el desarrollo social de los países que integran el espacio de la moneda común.

\section{Costes por pérdida de independencia monetaria}

Sin lugar a dudas, si existe un coste que se debe asumir por formar parte de una moneda única, ese es la pérdida de la independencia monetaria. Así, la política monetaria y la fijación del valor de la moneda son algunos de los principales instrumentos en política económica -junto a la política fiscal- que un gobierno tiene a su alcance para incidir en la economía nacional. La cesión de esta competencia, como ocurrió en el caso del euro en el Tratado de la Unión Europea (Tratado de Maastricht), implica riesgos, puesto que, es posible, que la política monetaria común se fije con carácter restrictivo, esto es, con un alto valor de la moneda, cuando uno de los países miembros pasa por una recesión profunda; decisión que le afecta directamente. Sin embargo, esa misma decisión puede ser conveniente para la mayoría de los países miembros.

No es este el momento ni el lugar para examinar esta situación con detalle, pero sí señalaré que estas situaciones económicamente endemoniadas se producen con mayor posibilidad a medida que sean más heterogéneas las economías que integran la moneda común, de ahí, una vez más, la importancia de los criterios de acceso a la moneda, así como el compromiso de solidaridad económica entre los Estados que la comparten (Frankel y Rose, 1998).

\section{CONCLUSIONES}

El proyecto de moneda única suramericana es, sin lugar a dudas, una ambición apasionante que, sobre el papel, aportaría beneficios generales y, se dice, consolidaría el proceso de integración latinoamericano. Basta examinar la 
realidad política y económica de esta zona del mundo, al margen de los problemas técnicos que he señalado en las líneas anteriores, para comprobar que una implantación real de este proyecto, al menos en el corto y medio plazo, se presenta como un reto imposible. Veamos algunos detalles básicos.

En primer lugar, la moneda única no puede ser el acicate para un proceso de integración en el ámbito de Unasur; lo razonable es que sea la consecuencia de un proceso de integración realizado. Un proceso que, a día de hoy, puede ser calificado de meramente testimonial pues ningún país plantea lo que es el requisito indispensable para llevar a buen puerto un proceso de integración en general, y monetario, en particular: la cesión de soberanía.

En segundo lugar, tampoco existe el compromiso político firme y decidido de los Estados. La solidaridad de los países latinoamericanos más prósperos respecto a los más desfavorecidos, con la creación de fondos estructurales que permitan la transferencia de recursos de los primeros a los segundos, parece, a día de hoy, una quimera.

En tercer lugar, no existe un mercado único que sea el espacio natural de una moneda común. Mercosur podría ser el inicio, como se señaló en su momento, y la base para la creación de un mercado que aglutine a todos los países latinoamericanos que se integraran en la zona de la moneda común. No obstante, ello, casi con toda probabilidad, implicaría el ingreso como miembros de pleno derecho, de los paí- ses que empleen la moneda común. Así, en la práctica, la moneda dependería de Unasur, y la regulación del mercado, de Mercosur. Ante semejante disparate, no es descabellado prever una fusión de Mercosur en la Unasur; una realidad que plantea problemas jurídicos que no podemos tratar aquí pero que, esencialmente, se manifestaría en la pérdida de la hegemonía de Brasil en dicho mercado, algo que muy difícilmente aceptaría este país.

En cuarto lugar, y aun superando toda la problemática señalada, que no es poca, nos encontraríamos con la realidad económica. Los miembros de Unasur distan mucho de ser economías similares en números relativos, y conseguir esa aproximación exige no solo tiempo sino también transferencias de recursos económicos desde las naciones más prósperas hacia las más desfavorecidas, una ejecución que no parece viable si dicha aproximación se quisiera realizar a medio plazo.

Por todo ello, si bien en el ámbito teórico las ventajas superan a los inconvenientes, la moneda única suramericana parece proyectarse hoy, más como un proyecto ideológico, como un camino a seguir o estudiar, que como una posibilidad real. Los requisitos necesarios, para una correcta operatividad de esta nueva moneda, parecen demasiado ambiciosos para poder conseguirse a medio plazo. En definitiva, el proceso de integración no está suficientemente maduro, a mi juicio ni tan siquiera levemente maduro, para plantearse materialmente la ejecución de un proyecto de esta envergadura. Así las cosas, mientras un proceso 
de integración bien definido, con una cesión de soberanía efectiva por parte de los Estados no sea implementado, la moneda única será únicamente un sueño ideológico, una moneda en la encrucijada.

\section{Referencias}

1. Anchuelo, A. (1998). Consecuencias económicas del euro. Madrid: Cívitas.

2. Bini Smaghi, L. y Casini, C. (2000). Monetary and Fiscal Policy Co-operation: Institutions and Procedures in EMU. Journal of Commom Market Studies, 38(3), 375-391.

3. Blinder, A. S. (1999). El Banco Central: teoría y práctica. Barcelona: Antoni Bosch.

4. David, J. H. (1978). La política monetaria. México: Fondo de Cultura Económica.

5. De Grauwe, P. (1994). Teoría de la integración monetaria. Hacia la Unión Monetaria Europea. Madrid: Colegio de Economistas de Madrid/Celeste Ediciones.

6. De la Dehesa, G. (1998). El reto de la unión económica y monetaria. Madrid: Instituto de Estudios Económicos.

7. Díaz Barrado, C. M. (2005). La Comunidad Suramericana de Naciones: propuestas y realizaciones. Revista Española de Derecho Internacional, 57(2), 639-663.
8. Dieterich, H. (1979). Vinculación entre las políticas fiscal y monetaria: avances y experiencias recientes. México: Centro de Estudios Monetarios Latinoamericanos.

9. Fernández Navarrete, D. (1999). Historia y economía de la Unión Europea. Madrid: Editorial Centro de Estudios Ramón Areces.

10. Frankel, J. A. y Rose, A. K. (1998). The Endogenity of the Optimum Currency Area Criteria. The Economic Journal, 108(449), 1009-1025.

11. Garay Salamanca, L. J. (1994). América Latina ante el reordenamiento económico internacional. Bogotá: Editorial Universidad Nacional.

12. Gutiérrez del Castillo, C. (1997). La Unión Monetaria Europea: cuestiones fundamentales. Revista de las Cortes Generales, (40), 351-357.

13. Hobsbawm, E. (2011). Cómo cambiar el mundo. Barcelona: Crítica.

14. Huntington, S. P. (1991). The Third Wave. Democratization in the Late Twentieth Century. Oklahoma: University of Oklahoma Press.

15. Krugman, P. (2009). The return of depression economics and the crisis of 2008. New York: W. W. Norton \& Co. 
16. Martínez Dalmau, R. (2005). La independencia del Banco Central Europeo. Valencia: Tirant lo Blanch.

17. Martínez Dalmau, R. (2007). Lecciones de unificación monetaria europea y particularidades sobre la integración latinoamericana. Observatorio de Análisis de los Sistemas Internacionales, (12), 433-450.

18. Nitsch, V. (April, 2002). Honey, I Just Shrunk the Currency Union Effect on Trade. World Economy, 25(4), 457-474.

19. Nun, J. (2015). El sentido común y la política. Buenos Aires: Fondo de Cultura Económica.

20. Persson, T. (2001). Currency Unions and Trade: How Large Is the Treatment Effect? Economic Policy, 16(33), 435-448. Obtenido de jstor: http://www.jstor.org/stable/1344648.

21. Rose, A. K. (1999). One Money, One Market: Estimating the Effect of Common Currencies on Trade. NBER Working Papers
7432. Obtenido de faculty: http://faculty. haas.berkeley.edu/arose/Grav.pdf

22. Sáez Fernández, F. J. (1994). El modelo europeo hacia una unión económica y monetaria. Granada: Universidad de Granada.

23. Sebastian, H. (2002). Winston Churchill: Una biografía. Madrid: Ediciones Destino.

24. Stiglitz, J. E. (2012). The price of inequality. New York: W.W. Norton \& Co.

25. Tenreyro, S. (2001). On the causes and consequences of currency unions. Obtenido de faculty: http://faculty.haas.berkeley. edu/arose/tenreyro.pdf

26. Unasur. (2014). Un espacio de cooperación e integración para el desarrollo. Obtenido de repositorio: http://repositorio.cepal. org/bitstream/handle/11362/37353/ S1420796_es.pdf?sequence $=1$

27. Yeager, L. (1984). Relaciones monetarias internacionales. Historia y política (Vol. 2). Madrid: Alianza Editorial Textos 